\title{
A FENOMENOLOGIA COMO MÉTODO DE INVESTIGAÇÃO DO DESIGN DE EXPERIÊNCIA ${ }^{1}$
}

\author{
Ms. Wagner Bandeira \\ Universidade Federal de Goiás \\ wbandeira@ufg.br \\ Dr. Cleomar Rocha \\ Universidade Federal de Goiás \\ cleomarrocha@gmail.com
}

\begin{abstract}
Resumo: O design de experiência tem ganhado grande espaço nos projetos de interface gráfica em função de sua centralização no usuário em seu contexto de uso, cuja demanda cresce na relação direta dos desenvolvimentos tecnológicos. No entanto, verifica-se uma lacuna no que tange aos modelos metodológicos para os estudos da experiência do usuário. Tomado como um método que considera a relação entre eu e o mundo na busca da essência das coisas, a Fenomenologia se caracteriza como essencial para o estudo das experiências humanas com o mundo. $\mathrm{O}$ presente artigo apresenta alguns dos princípios fundamentais da metodologia fenomenológica elaborada pelo filósofo Edmund Husserl e desenvolvida posteriormente por Maurice Merleau-Ponty. Em seguida estes princípios são relacionados com a prática de avaliação da relação usuário-sistema via interface verificando os elementos que caracterizam a experiência. Enquanto uma proposta teórica de natureza especulativa, adota-se uma abordagem indutiva, para estabelecer estas relações e propor princípios para implementação posterior nas pesquisas de interfaces gráficas.
\end{abstract}

Palavras-chave: método fenomenológico; experiência do usuário; design de interface

\begin{abstract}
The experience design has been an object of great interest in graphic interface design because of its focus on the user in its using context, which demand increases in direct relation with technological development. However, one can verify a gap between the methodological models for the user experience studies. Used as a method which considers the subject-object relationship in the search for the essence of the things, the Phe-
\end{abstract}

\footnotetext{
${ }^{1}$ Este artigo é parte de uma pesquisa com financiamento da Fundação de Amparo à Pesquisa do Estado de Goiás - FAPEG.
} 
nomenology is taken as essential for the study of human experience with the world. This paper presents some of fundamental principles of phenomenological methodology elaborated by the philosopher Edmund Husserl and later developed by Maurice Merleau-Ponty. Afterwards, these principles are related with the evaluation practice of user-interface relationship verifying the elements that typifies the experience. As a theoretical proposal of speculative nature, it takes an deductive approach of thinking to establish these relations and to propose a model for the later implementation on graphic interfaces researches.

Keyowords: phenomenological method; user experience; interface design

\section{INTRODUÇÃO}

Retornar às coisas mesmas como método de desvelamento: objetivo principal da prática fenomenológica em contraste aos posicionamentos cientificistas empiristas e psicologistas. Sob esse fundamento o método fenomenológico encontra nas ciências humanas extrema importância pelo modo como pretende chegar ao conhecimento, caracterizando-se como uma proposta sólida de investigação qualitativa da experiência humana, "deixando de lado as especulações metafísicas abstratas e entrando em contato com as 'próprias coisas', dando enfoque à experiência vivida" (MOREIRA, 2002, p.62)

Orientado à pesquisa "Projeto de interface para sistema de gestão de aprendizagem" busca-se analisar se tal método é adequado para oferecer subsídios à verificação das experiências do usuário em relação às interfaces gráficas.

Enquanto proposta metodológica, a fenomenologia se orienta para um pensamento dialético entre o empirismo e o idealismo em relação à busca da essência das coisas. Se essa busca se dá por meio da experiência, ou se esta é parte do processo de percepção dos fenômenos, espera-se que pelos desdobramentos teóricos e pragmáticos da abordagem fenomenológica o designer possa empreender o desenvolvimento de um projeto centrado na experiência do usuário, também chamado de "Design de Experiência".

O presente artigo apresenta alguns dos princípios fundamentais da metodologia fenomenológica buscando relacioná-la com a pesquisa demandada. Por se tratar de uma investigação exploratória, de verificação indutiva, embora o método usado neste artigo tenha caráter notoriamente bibliográfico, em suas relações teóricas, com articulações de base dedutivas. Entrementes, na adoção do método aqui defendido, a prática estabelecida mantém fiel à lógica indutiva, pelo já declarado caráter exploratório na visada pragmatista adotada. Para isso será feita, após uma leitura descritiva do método, a apresentação do contexto da pesquisa para, em seguida dirigir-se à discussão do método fenomenológico, buscando estabelecer a relação entre método e objeto, em seu sentido estrito. Ao fim do trabalho pretende-se verificar quais aspectos da proposta fenomenológica se apresentam como mais adequados à referida pesquisa e como se dá essa relação. 


\section{PRINCÍPIOS DA FENOMENOLOGIA}

Apresentado por Edmund Husserl a partir de trabalhos sintetizados em obras como "A ideia da Fenomenologia", o método fenomenológico apresenta-se como uma orientação pragmática de busca das essências das coisas. Em uma orientação dialética entre aquele que percebe o mundo e as coisas percebidas, essa escola filosófica se propõe a dialogar com os princípios do idealismo e do empirismo, não por meio da negação de seus princípios, mas da correlação entre suas propostas.

O idealismo, cujas raízes estão no cogito cartesiano, fundamenta a percepção da realidade a partir da razão pura. Nesse sentido, tem-se um certo ceticismo em relação ao mundo, na medida em que este não é mais do que o resultado do conhecimento que temos dele. Todas as coisas são postas em dúvida para que, por meio da submissão ao rigor metodológico, a razão possa chegar à certeza de sua existência.

O empirismo, de cujas propostas as manifestações positivistas são importantes representantes, se fundamenta na percepção das coisas antes da razão. Desse modo, nega-se a subjetividade e a relação do sujeito com a coisa se dá de forma passiva. Para esse modelo metodológico, mesmo o pensamento pode ser objetivado, quantificado e mensurado. Sua prática, enquanto abordagem política/sociológica demonstrou suas desastrosas consequências, embora ainda se faça presente em grande parte do pensamento capitalista ocidental.

A fenomenologia, como uma síntese dialética, surge como o estudo das essências que se dão por meio do reconhecimento dos fenômenos. Esse reconhecimento é dinâmico e relacional. Sendo assim, o ser pensante somente se faz presente no momento de sua relação com o objeto pensado. Portanto, não há a primazia do cogito uma vez que este somente se faz a partir do mundo pensado, que o antecede. E este mundo, por sua vez, somente existe a partir do pensante ou, nas palavras do fenomenólogo Merleau-Ponty (1999, p.13) “Portanto, não é preciso perguntar-se se nós percebemos verdadeiramente o mundo, é preciso dizer, ao contrário: o mundo é aquilo que percebemos".

Como consequência desse pensamento fenomenológico, surge uma outra postura quanto ao conhecimento das coisas, porquanto de sua verificação não mais como objetos estáticos pré-existentes e imutáveis, mas como resultantes da relação com aquele que os observa. No campo das ciências humanas, essa orientação ganha corpo na medida de sua adequação às constantes transformações do comportamento humano.

A partir dessa proposição de Husserl, o filósofo francês Maurice Merleau-Ponty sistematizará algumas de suas definições para o que se desdobrará em seus seguidores como um método para a busca do conhecimento, em um exercício hermenêutico. Sua leitura avançará mais ainda nas questões da percepção como modo de estabelecimento desta relação fenomenológica, que trará, como resultante, dentre outros, a leitura de uma observação mais ampla dos fenômenos para além de sua superfície sensorial.

Sua contribuição para a leitura das experiências se dará conquanto está exposto o paradoxo da imanência e da transcendência, que somente pode ser respondida pela experiência do mundo.

Enquanto a extensão do mundo percebido expande-se, também o faz a concepção de Merleau-Ponty sobre a fenomenologia, em cujo texto torna-se o método geral para o entendimento do paradoxo 
inerente do percebido: uma realidade é percebida somente na medida em que é experimentada, e além disso, sempre "para mim". Mas a coisa percebida, para ser real, deve também apresentar-se como "coisa mesma", ou seja, como precedendo e excedendo minha experiência sobre ele. (TOADVINE, 2008, p. 20, tradução nossa)

A fenomenologia em Merleau-Ponty verifica que a experiência se dá na percepção do todo, imanente e trasncedente, como interconectados, dando origem a uma reflexão ad infinitum da coisa e do eu. Em síntese:

Todo o universo da ciência é construído sobre o mundo vivido, e se queremos pensar a própria ciência com rigor, apreciar exatamente seu sentido e seu alcance, precisamos primeiramente despertar essa experiência do mundo da qual ela é a expressão segunda. (MERLEAU-PONTY, 1999, p.3)

\section{O DESIGN DE EXPERIÊNCIA EM PROJETOS DE INTERFACE GRÁFICA}

Surgido de forma mais sistematizada a partir dos estudos de usabilidade em interfaces gráficas, o design de experiência do usuário (algumas vezes abreviado do inglês UX - user experience), tem como orientação a relação do usuário com o produto de design na perspectiva das experiências obtidas no seu contato, por meio do uso, acesso ou leitura.

Algumas lacunas conceituais tem orientado grande parte dos trabalhos que discutem o design de experiência na medida em que definem essa área pela intenção em promover exclusivamente condições de usabilidade do sistema. Isso se caracteriza como inadequado pois é possível que os interesses da usabilidade e da experiência estejam até mesmo em conflito direto:

\footnotetext{
Interagindo com uma representação virtual usando um dispositivo físico (ex. Batendo uma marreta de plástico em um prego virtual representado na tela do computador) comparado com o modo mais eficiente de realizar a mesma tarefa (ex. Selecionando uma opção usando teclas de comando) pode requerer maior esforço, mas poderia, ao contrário, resultar em uma experiência mais divertida e aproveitável. (SHARP, H; ROGERS, Y; PREECE, J., 2007, p. 19-20, tradução nossa. Destaque do autor)
}

Na mesma linha de pensamento, alguns trabalhos afirmam a experiência como algo provocado intencionalmente em cuja falha estaria sua ausência:

Mas a peculiaridade do design para experiência está no fato de o produto deste design não ser previsível. Além disso, ele pode não se consolidar de fato, ou seja, experiências podem não ocorrer. No entanto, a não previsibilidade do resultado final e a sua não existência é um dado previsto pelo designer. (NOJIMOTO, 2009, p.31)

Em John Dewey (2010), verifica-se que todas as relações com a natureza se caracterizam como experiências. $O$ que se pode diferenciar, segundo o autor, no fluxo da 
vida cotidiana como algo a se marcar ou adotar determinado valor é o que ele chamará de "experiência singular", uma relação específica, considerada pela pessoa em função de valores internos e contextos específicos.

A experiência ocorre continuamente, porque a interação do ser vivo com as condições ambientais está envolvida no próprio processo de viver. [...]

As coisas são experimentadas, mas não de modo a se comporem em uma experiência singular. Há distração e dispersão; o que observamos e o que pensamos, o que desejamos e o que obtemos, discordam entre si. [...]

Em contraste com essa experiência, temos uma experiência singular quando o material vivenciado faz o percurso até sua consecução. Então, e só então, ela é integrada e demarcada no fluxo geral da experiência proveniente de outras experiências. (DEWEY, 2010, p.108)

É possível, por conta dessa experiência singular ser demarcada como a experiência de fato, que se releve o papel das experiências cotidianas como não dignas de notação e, até perceptivamente inexistentes. Dewey fala em experiência cotidiana e a singular. Ambas de fato. A singular é digna de observação, mas a rotineira, comum, é completa porque é experiência. Contra a experiência concorrem a dispersão e a distração. Afora isto, a experiência é completa, ainda que comum.O risco desta postura, no âmbito do design de experiência, coloca-se no fato de, para o designer, perder-se a dimensão fenomenológica do usuário com o objeto e elegerem-se algumas experiências gerais como metas a serem alcançadas e ignorarem as situações simples, não demarcadas por grandes eventos. Em outros termos, a singularização não mantem relação de proporcionalidade com a complexidade do projeto ou da ação proposta ao usuário. A singularidade está na densidade da experiência e em sua condição de completar-se.

Pode ter sido algo de tremenda importância - uma briga com alguém que um dia foi íntimo, uma catástrofe enfim evitada por um triz. Ou pode ter sido algo que, em termos comparativos, foi insignificante - e que, talvez por sua própria insignificância, ilustra ainda melhor o que é ser uma experiência. (DEWEY, 2010, p.109)

Ainda que os estudos no campo de Design de Interface tenham trazido nos últimos anos essa discussão à tona, a prática do design de experiência remonta à origens do próprio design, na medida em que o mesmo estabelece a relação entre objeto e usuário. Concluindo o pensamento sobre a crise do design em suas definições originais, Giulio Argan argumenta, a partir da relação de sujeito e objeto o papel do design:

Explica-se, assim, o design como processo da existência finalística não apenas da sociedade, mas de toda a realidade; é o design que promove uma coisa ao grau de objeto e coloca o objeto como perfectível, ou seja, participante do finalismo da existência humana.

(ARGAN, 1998, p. 252) 
No entanto, embora sempre presente, a experiência somente se torna central na decisão projetiva a partir do deslocamento do foco do projeto de suas dimensões funcionais, ergonômicas e subjetivas para uma dimensão contextual, com o fiel da balança pendendo para esta última enquanto modelo projetivo. No trabalho em que discute o design dos produtos do dia-a-dia, o designer inglês Donald Norman, traz para o debate o fato de que essa relação com o objeto vai além do contato funcional ou estético com o produto. Em sua obra mais aclamada, o autor apresenta diversas demonstrações de como os produtos que nos cercam falham justamente na medida em que esquecem estar lidando com seres humanos em todas as suas imprevisibilidades.

\begin{abstract}
Nossas vidas se tornam mais complicadas por conta de máquinas que não conseguem lidar com as reais complexidades do mundo. 0 design de máquinas que consigam se relacionar com todas as complexidades, e especialmente com o inesperado, não será possível por um longo tempo. No entanto, há muito o que pode ser feito para ajudar. Um caminho significante é [...]: tornar bastante simples o pedido de auxílio de um humano. Um segundo problema tem a ver com a filosofia de design muito seguida pelos designers dessas máquinas: a falta de empatia dos designers com as pessoas que devem usá-las.
\end{abstract}

(NORMAN, 2011, p.112, tradução nossa)

Em uma definição mais recente o designer Jesse James Garret traz uma definição mais explícita da relação da experiência com as outras dimensões do produto:

O design de experiência do usuário dialoga com questões de contexto. $O$ design estético garante que o botão da cafeteira tem uma forma e textura atraentes. $O$ design funcional garante que aquele irá acionar devidamente o dispositivo. $O$ design de experiência do usuário garante que os aspectos estéticos e funcionais do botão trabalhem no contexto das outras partes do produto, fazendo perguntas como, "O botão não é pequeno demais para uma função tão importante?" O design de experiência também garante que o botão trabalhe no contexto no qual o usuário está tentando realizar, perguntando, "O botão está no lugar certo em relação aos demais controles que o usuário deveria usar ao mesmo tempo?" (GARRET, 2011, p.8, tradução nossa)

Enquanto um projeto voltado para a educação por meio de uma interface gráfica no qual o usuário tem acesso a uma série de recursos interativos, informacionais e visuais, o projeto de Ambiente de Gestão de Aprendizagem, desenvolvido como parte do doutorado no curso de Pós-graduação em Arte e Cultura Visual da UFG, elege o design de experiência como referência teórico-prática, na medida em que verifica que o produto do design não deverá estar centrado na sua tecnologia para a funcionalidade, nem tampouco para uma estética específica. Sua orientação será, deste modo, focada na experiência do usuário, na medida do uso dessa solução de interface como mediador de acessos aos recursos dos diversos ambientes informativo da rede de computadores. Por conseguinte, o modelo se alinha à vertente pragmatista, em uma verificação de contexto de uso, o continuum do ser no mundo, de que fala a fenomenologia. 
Se seus contornos conceituais carecem de uma definição mais precisa, ainda que não necessariamente consensual, do ponto de vista metodológico, o design de experiência não encontrou ainda um subsídio mais estruturado, sendo desenvolvido a partir práticas psicológicas de interação sujeito-objeto sem um contorno metodológico definido.

Neste sentido, cabe uma discussão acerca do método fenomenológico como proposta estruturada a fim de orientar a prática do design de experiência nos aspectos dessa relação do eu cognoscente com as coisas do mundo. Para isso, apresenta-se a seguir uma descrição desse método, intercalando aspectos de inserção na prática de análise e desenvolvimento do design de experiência.

\section{O MÉTODO FENOMENOLÓGICO}

A partir da concepção da relação consciência-mundo, Merleau-Ponty sistematiza alguns dos fundamentos da fenomenologia de Husserl que culmina em uma orientação metodológica para a busca do conhecimento das coisas.

Sua dimensão pragmática caracteriza-se em uma outra postura do filósofo/pesquisador em relação não somente ao mundo, mas ao outro, entendido como sujeito pré-existente, personagem também do paradoxo. Surgem aqui quatro aspectos deste método que, de forma sistematizada, quase cartesiana, oferecem caminhos para a apreensão do conhecimento.

O primeiro desses aspectos se fundamenta na verificação do privilégio da descrição fenomenológica sobre a explicação científica e reconstrução idealista. A fenomenologia deve pôr de lado todas as explicações científicas de percepção e percebido a fim de investigar a experiência pré-científica que tal explicação tem por correto.

O real deve ser descrito, não construído ou constituído. Isso quer dizer que não posso assimilar a percepção às sínteses que são da ordem do juízo, dos atos ou da predicação. (MERLEAU-PONTY, 1999, p.5)

Uma vez que o foco está na descrição das essências, já não vale, para este princípio, levar em consideração, em primeira instância, as explicações científicos previamente dadas, ou mesmo os de senso comum, posto que estes ofuscam a experiência mesma do fenômeno. No entanto,

a fenomenologia não rejeita, enfim, a explicação científica ou os objetos científicos que ela postula. Ela somente insiste que o mundo experimentado é direta ou indiretamente a fundação de toda a reinvindicação legitimada da ciência. Deste modo, todas as explicações científicas e objetos teóricos confirmam a existência de tempo, mas a unidade de tempo, Merleau-Ponty argumenta, é fundada na experiência perceptiva e, consequentemente, "toda consciência é perceptiva". (TOADVINE, 2008, p. 22, tradução nossa)

No âmbito do design de experiência, essa etapa caracteriza a suspensão das afirmações anteriores acerca da relação usuário-sistema, no qual se buscam, muitas vezes, relacionar aspectos de habilidade em relação ao sistema com um determinado 
letramento linguístico do usuário. O reconhecimento de elementos da interface, como já argumentava Donald Norman, podem ser assimilados por elementos simples como a visibilidade do sistema que, por sua vez, não se caracteriza necessariamente por um destaque específico, mas pelo posicionamento previsível do mesmo em relação à ação do usuário.

Nesta dimensão, não há um interesse específico pelo estabelecimento de relações de causa e efeito, tampouco a corroboração de hipóteses. Sua leitura é predominantemente descritiva, orientada pela experiência do observador em relação às experiências do usuário da interface. Qualquer comportamento, reação ou escolha deve ser identificada ainda que não se verifique uma posterior relação com o todo do fenômeno. Elementos invariáveis surgirão nesse processo (como as que caracterizam as expectativas do usuário), em uma análise a posteriori, mas cuja relação com o usuário somente poderá ser entendida com as etapas seguintes do método.

O segundo aspecto apontado por Merleau-Ponty é tido como bastante controverso dada à fragilidade em sua verificação. Trata-se da chamada Redução Fenomenológica ou epoché. Trata-se esta da suspensão temporária dos envolvimentos práticos de modo a trazê-los à luz. Caracteriza-se pela libertação dos (pre)conceitos que orientam o pensamento para a busca do conhecimento.

E porque somos do começo ao fim relação ao mundo que a única maneira, para nós, de apercebermo-nos disso é suspender este movimento, recusar-lhe nossa cumplicidade [...], ou ainda colocá-lo fora de jogo. Não porque se renuncie às certezas do senso comum e da atitude natural - elas são, ao contrário, o tema constante da filosofia -, mas porque, justamente enquanto pressupostos de todo pensamento, elas são "evidentes", passam despercebidas e porque, para despertá-las e fazê-las aparecer, precisamos absternos delas por um instante. (MERLEAU -PONTY, 1999, p.10)

Esse é um posicionamento que exige uma nova postura do pesquisador, na medida em que ele deve buscar um novo olhar sobre as coisas. Ainda que estas Ihe sejam comuns, ele precisa isolar todos os conceitos anteriores sobre as coisas que observa e ver novamente como experiências fundantes. Como afirma Merleau-Ponty, essa etapa não é uma negação do conhecimento anterior, mas uma forma de enxergar sob outra perspectiva.

Na prática do design de experiência, o usuário já não é visto como um indivíduo genérico, estereotipado em função de algum contato superficial. Neste momento ele já possui certa identidade, e a relação que estabelece com o projeto de interface já se dá na medida de suas relações pessoais com o mesmo.

O modelo mental de realização de tarefas, muitas vezes elaborados a partir de levantamentos gerais do comportamento do usuário médio, é colocado em perspectiva, e busca-se uma nova orientação para a prática específica contextualizada do usuário. Visto que todos os modelos são suspensos, pode-se verificar comportamentos completamente imprevisíveis, ainda que comuns e invisíveis ao olhar desatento.

A terceira etapa é chamada de Redução Eidética, ou a busca pela essência. $O$ encontro das essências se dá pela experiência de nós mesmos. A essência, no entanto, não nega a existência, nem se associa à linguagem que a denomina, mas relaciona-se àquilo que ela é para nós. 
Buscar a essência do mundo não é buscar aquilo que ele é em ideia, uma vez que o tenhamos reduzido a tema de discurso, é buscar aquilo que de fato ele é para nós antes de qualquer tematização. $[\ldots]$

A redução eidética, ao contrário, é a resolução de fazer o mundo aparecer tal como ele é antes de qualquer retorno sobre nós mesmos, é a ambição de igualar a reflexão à vida irrefletida da consciência.(MERLEAU -PONTY, 1999, p.13)

Abre-se o espaço para a imaginação, uma vez que aqui a consciência volta-se para uma universalização da essência da coisa pensada. Buscam-se variações possíveis sobre uma coisa, e busca-se encontrar o que torna impossível as outras variações, no que é a essência da própria coisa. Não é uma busca pela essência ideal, teorizada, mas a essência que parte da existência, como a coisa era antes de ser teorizada.

Para o designer de experiência, a relação usuário-sistema, encontra sua essência nas práticas mais fundamentais. O que Norman caracteriza como Psicologia das Coisas Cotidianas (NORMAN, 1988) visa verificar como se dão as relações mais simples, antes de reconfigurarem-se os objetos pelos seus contornos simbólicos e culturais. 0 acionamento de um comando se dá ao disparar um botão, o botão deve ser selecionado e acionado, o acionamento pode ser pela pressão, puxamento, giro ou deslocamento linear. A escolha pelo modelo apropriado será encontrado quando se verificar qual a essência do botão em relação ao acionamento do usuário. A redução eidética acontece quando se eliminam todas os elementos não essenciais para que um botão seja entendido como tal.

O quarto e último momento do método fenomenológico é o que Husserl aponta como intencionalidade. Ela trata do reconhecimento de que toda consciência é consciência de alguma coisa. Neste sentido, a percepção não se dá integralmente na consciência e nem a coisa percebida está livre desta, mas há um fluxo de percepção constante a partir da consciência de algo. A coisa existe, não de modo idealista como o cogito cartesiano que aprisiona tudo na consciência - mesmo porque a intencionalidade parte do princípio de se viver em um mudo já existente - , nem de modo empirista do positivismo que subtrai a consciência para uma objetivação de tudo. Estabelece-se uma relação dialética entre perceptor e percebido. Isso conduz a uma compreensão fenomenológica em que tudo tem uma significação.

\footnotetext{
Trata-se de reconhecer a própria consciência como projeto do mundo, destinada a um mundo que ela não abarca nem possui, mas em direção ao qual ela não cessa de se dirigir - e o mundo como este indivíduo pré-objetivo cuja unidade imperiosa prescreve à consciência a sua meta.

[...] Em relação a elas, não há uma palavra, um gesto humano, mesmo distraídos ou habituais, que não tenham uma significação. (MERLEAU -PONTY, 1999, p.15-16)
}

Isso compromete o observador a investigar todas as relações possíveis como interconectadas, posto que a consciência não se caracteriza como "uma substância, mas uma atividade constituída por atos (percepção, imaginação, volição, paixão etc) com os quais visa algo" (MOREIRA, 2002, p. 85). Merleau-Ponty caminha para uma vi- 
são holística dos fenômenos.

Deve-se compreender a história a partir da ideologia, ou a partir da política, ou a partir da religião, ou então a partir da economia? Deve-se compreender uma doutrina por seu conteúdo manifesto ou pela psicologia do autor e pelos acontecimentos de sua vida? Deve-se compreender de todas as maneiras ao mesmo tempo, tudo tem um sentido, nós reencontramos sob todos os aspectos a mesma estrutura de ser. (MERLEAU-PONTY, 1999, p.17)

Para o designer de experiência essa é a etapa em que todas as ações consequentes da relação do usuário com o sistema são consideradas em todas as suas dimensões. A experiência passa a ser resultante da relação contextual das dimensões do usuário - biológica, cultural, ideológica, cognitiva - e do próprio sistema - funcionalidade, estética, ergonomia, referências - e verifica-se como se dá esse fluxo constante da consciência para o objeto.

Aqui reforça-se a questão das experiências constantes, na medida em que a relação nunca cessa. O usuário nunca deixa de pensar o sistema e seu pensamento só é possível em função deste. Volta-se aqui à questão fundante do design enquanto definidor da relação sujeito-objeto (ARGAN, 1998).

Não é possível pensar o usuário do sistema sem a existência do próprio sistema e mesmo do contexto que os antecede. E, nesta medida, é válido ao designer de experiência verificar as diversas dimensões contextuais da relação. Cabe a ele, designer, também questionar e compreender as razões de cada elemento, sua ontologia, a fim de tocar-lhe a face e sentir seu pulsar. Esta retomada à origem da coisa mesma funda 0 pensamento original, abrindo-se para projetos inovadores.

\section{EXPERIMENTANDO O MÉTODO}

Uma metodologia para o design de experiência se faz urgente na medida em que esta busca se estabelecer como prática do Design contemporâneo que tem como meta a melhor relação usuário-objeto. No campo das interfaces gráficas, a experiência se caracteriza como uma percepção de todas as dimensões dessa relação, como o corpo próprio se lança e está no mundo. E ele o é integralmente, corpo e mente, compondo um só. E ao estar no mundo, diante ou não de uma interface, todos são um só contexto, o contexto de uso. A proposta fenomenológica vem se apresentar como um caminho para essa discussão.

As questões aqui apresentadas não almejam ser exaustivas nem tampouco conclusivas, uma vez que arranham a superfície de uma filosofia que se apresenta de modo denso e especulativo. Desta forma, ainda há muito espaço para reflexão sobre este tema, o que se faz urgente na medida de sua inserção no crescente universo das tecnologias de informação e comunicação.

Se há uma crítica ao estabelecimento deste método, esta coloca-se em sua própria assertiva fundamental, a saber, o retorno às essências. Se por um lado, ela oferece uma visão mais ampla da relação usuário-sistema, sua amplidão demanda uma energia que pode ser demasiada para o pesquisador, mas absolutamente premente para se desvelar a relação do ser no mundo, diante de telas repletas de informações atualizadas e nuvens carregadas de virtualidades informacionais. 


\section{REFERÊNCIAS}

ARGAN, Giulio C. História da arte como história da cidade. São Paulo: Martins Fontes, 1998.

DEWEY, John. Arte como Experiência. São Paulo: Martins Fontes, 2010.

GARRET, Jesse J. The Elements of User Experience: User-Centered Design for the Web and Beyond. Berkeley: New Riders, 2011.

MERLEAU-PONY, Maurice. Fenomenologia da percepção. São Paulo: Martins Fontes, 1999.

MOREIRA, Augusto. 0 método fenomenológico na pesquisa. São Paulo: Pioneira/Thompson, 2002.

NOJIMOTO, Cynthia. Design para experiência: processos e sistemas digitais. 2009. 212 f. Dissertação (Mestrado em Arquitetura e Urbanismo) Escola de Engenharia da Universidade de São Paulo, São Carlos, 2009.

NORMAN, Donald. The Design of Everyday Things. New York: Doubleday, 1988. . Living with complexity. Cambridge: The MIT Press, 2011.

TOADVINE, Ted. Phenomenology and "hyper-reflection". In.: DIPROSE, R.; REYNOLDS, J. Merleau-Ponty: key concepts. Stocksfield: Acumen, 2008. P.17-29.

SHARP, H; ROGERS, Y; PREECE, J. Interaction Design: beyond human computer interaction. Londres: John Wiley, 2007. 